\title{
Chapter 12 \\ The Role of Earthquake Insurance in Earthquake Risk Reduction and Resilience Building
}

\section{Fouad Bendimerad}

\begin{abstract}
Resilience is defined as "The ability to prepareand plan for, absorb, recover from and more successfully adaptto adverse events" (US National Academies). Resilience has four pillars: - Anticipate: the ability to anticipate and reduce the impact of shocks through preparedness and planning, $\bullet$ Absorb the ability to absorb and cope with the impacts of shocks and stresses. - Adapt: the ability to change in response to multiple, long-term and future risks, and to learn and adjust after a shock materializes. - Transform: the ability to take deliberate steps to change the systems that create risk, vulnerability and or inequality. How does insurance intervene in building resilience? The outcome of insurance is to restore property and livelihoods in case of an adverse effect. It does that by providing a cash infusion into the socio-economic system of the affected communities immediately after the event. The cash is used to restore property and avoid interruption of commercial and industrial activity. Insurance also intervenes in terms of reducing impact of stresses (which are the more extensive types of risk) since it enables a system of "maintenance" by providing funds for recovery under minor but more frequent events. For most developing countries, governments have been the insurer of last resort when it comes to catastrophe risk (referred to as Cat Risk in the insurance industry). The reason is that level of cat insurance penetration in most developing countries is very low, sometimes lower than $1 \%$. The assurance of government intervention coupled with the lack of effectiveness of the financial transaction associated with a traditional insurance policy negate any incentive for individuals to acquire a cat insurance policy. The Turkish Compulsory Insurance Program or TCIP is one of the early experiment to change that paradigm and to provide a meaningful role for cat insurance in emerging economies. After a slow start, TCIP has now developed the financial capacity and the spread of coverage to play a significant role both in the financing of risk but also in supporting earthquake risk reduction in Turkey. New cat insurance products based on parametric indexing have since emerged. These insurance products could further improve the efficiency of TCIP and other cat insurance pools by making them more attractive to individuals, thereby scaling up their contribution to building resilience.
\end{abstract}

F. Bendimerad $(\bowtie)$

EMI, 3F Puno Bldg. Annex 47, Kalayaan Avenue, Diliman, 1101 Quezon City, Philippines e-mail: fouadb@emi-megacities.org 


\subsection{Resilience and System Theory}

Resilience finds its theoretical basis in system theory. This is illustrated in Fig. 12.1. An urban system, in this case the city of Istanbul is a dynamic system subject to the five elements indicated in the figure. A system is resilient when negative environmental shocks and stresses cause the minimum impact to its outputs and will require minimum, if any external resources to maintain its positively productive steady state. An important point is that the resilience of a system is only as good as its weakest subsystem.

The value of resilience in any urban system (e.g., housing, transport, land use, etc.) is revealed by the risk diagram of Fig. 12.2, which shows what happens when insufficient resilience is designed into such system. Should a "system", prove to have too little resilience, it can go into a state of emergency even when a simple perturbation occurs. Conversely, should the initial state of the system has the necessary and sufficient resilience built-in from the start, then it should be able to sustain a "perturbation" and still maintain functionality, albeit at a some diminished mode of resilient operation. This means that a state of emergency within an urban system could potentially be averted should its initial design provide an appropriate level of resiliency.

In addition, the duration of the degraded operations would ostensibly be shorter with fewer critical systems being impacted. Finally, after the crisis comes to an end, the resilient systems could be built back safer using lessons learned. The new "normal" state would represent an even more resilient environment. We call this type of system "resilient risk-tolerant", as opposed to "unaware risk-averse". Risk-averse systems are those that cannot or will not accept that there are always risks involved; whereas resilient risk-tolerant ones are those that assess the risk and manage it by employing appropriate levels of resilience.

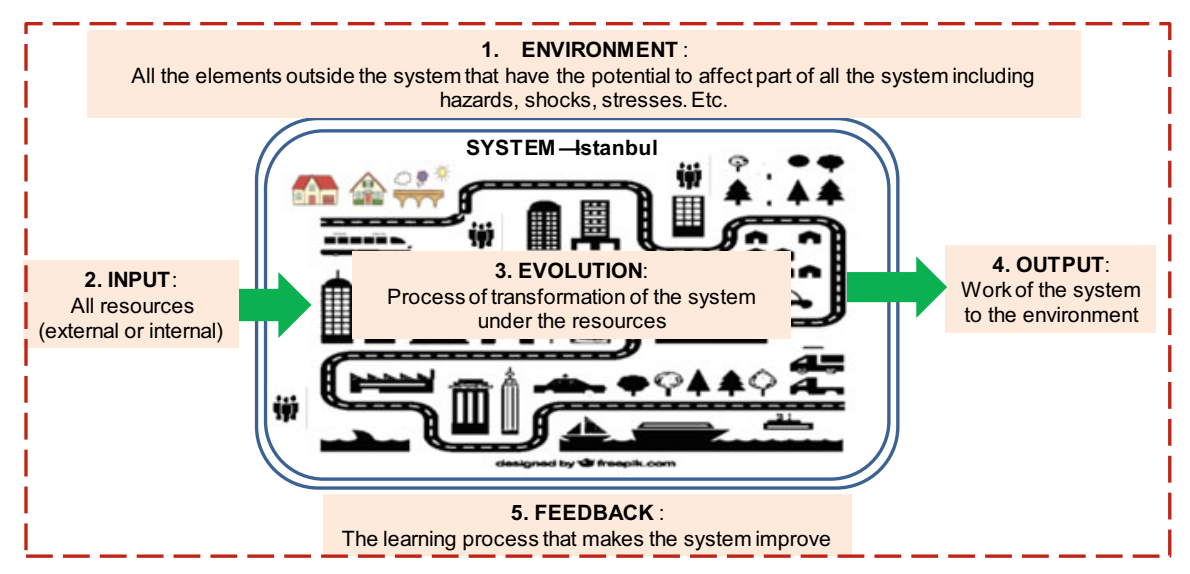

Fig. 12.1 Resilience finds its theoretical basis in system theory 


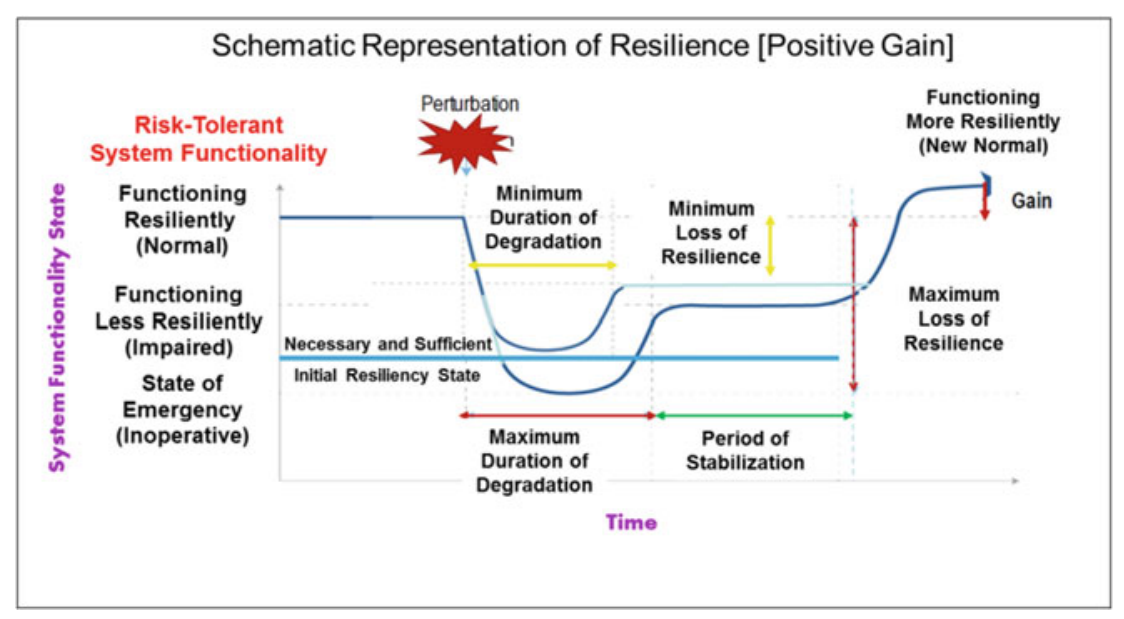

Fig. 12.2 Schematic representation of resilience indicating positive gain

Government can introduce several mechanisms to reduce risk. These may include structural investments, improve emergency response, as well as non-structural investments for awareness raising and capacity building. However, independently on how much investment society makes in reducing its risk, there is always some amount of risk that remains, called Residual Risk. This is where insurance intervenes. It offers the financial mechanism to finance residual risk. In the hypothetical example of Fig. 12.3, it is assumed that the combined outcome of all structural and nonstructural interventions of government and non-government entities has resulted in a $65 \%$ reduction in the potential losses from a disaster. The $35 \%$ risk that remains is the residual risk that can ideally be financed through insurance (Fig. 12.3).

\section{The Concept of Residual Risk

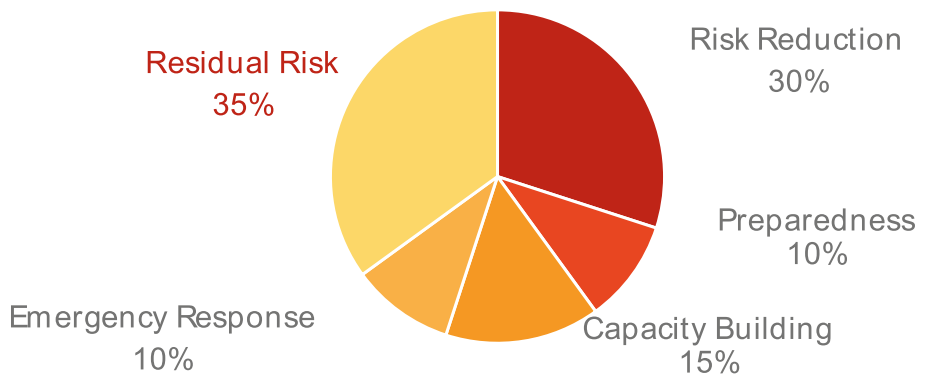

Fig. 12.3 Hypothetical case illustrating the residual risk concept 


\subsection{Insurance and Resilience}

Within this context, how does insurance intervene in building resilience?

The ultimate outcome of insurance is to contribute to the restoration of property and livelihoods in the case of an adverse effect on a system. It does that by providing a cash infusion into the system immediately after the event. The cash is used to restore property and avoid interruption of commercial and industrial activity. In reference to Fig. 12.1, Insurance is part of the Input of the system. It is essentially a resource to the system. The big advantage of insurance as a resource is that it is an immediate cash infusion. In fact, the faster the insurance funds are put back into the system, the more resilience capital the system has. This corollary indicates that parametric approaches to Cat Insurance are favored over indemnity approaches since, in principle the distribution of funds is much faster in the former than the latter.

Insurance also intervenes in terms of reducing impact of stresses (which are the more extensive types of risk) since it enables a system of "maintenance" by providing funds for recovery under minor but more frequent shocks.

Finally, a third form of insurance intervention is through awareness raising about hazards and risks. A well-informed community or a business has confidence in the viability of the system itself. For example, by insuring its asset, a business reduces its liability and is in better financial position to increase investment and productivity.

This of course, describes an ideal insurance governance system built on trust, transparency, and effectiveness. However, as explained below, there have been barriers to this "perfect" system in the past.

\subsection{How Does Cat Insurance Work?}

Cat insurance deals with providing insurance coverage against natural disasters such as earthquakes, floods, extreme winds, and others (Bendimerad and Home 1999). It is a specific business line of the insurance industry and has particular rules. The operations and functions of cat insurance are often not understood by the public. One of the main reasons, is that Cat Insurance is complex to underwrite and manage by insurers and regulators alike. Until recently, cat risk was considered as a "non-insurable" risk because of the unpredictability of losses (both in frequency and severity). The concern of both the insurer and the regulator is that big-loss events (high frequency-low severity events) will wipe out the insurer surplus thereby endangering compensation of the policyholders and potentially driving the insurer into bankruptcy. To reduce such a risk, the primary insurance tends to carefully control its exposure to cat risk, while at the same time seeking to cede most of the risk to one or more reinsurers. There are several forms of contracts between a primary insurer and the reinsurer, but they essentially have the same objective, which is to transfer a portion of the risk from the insurance to the reinsurer for a share of the premium. 
In the mid-nineties, catastrophe bonds (cat bonds) appeared on the capital market. These bonds enable both insurers and reinsurers to cede a portion of the risk directly to institutional investors on the capital market. Cat bonds offered a new way for the insurance industry to increase access to capital, thus improving its capacity to underwrite cat risk. Cat bonds proved to be of great interest to several institutional investors because they are not correlated to traditional investments such as the corporate stocks, corporate or government bonds, real estate derivatives and others. They offer investors an attractive option for portfolio diversification (Canabarro et al. 2000).

\subsection{Why Does Insurance Matter in Building Resilience?}

Insurance is vital to the economy of a country. For most countries, governments have been the insurer of last resort when it comes to cat risk. The reason is that level of cat insurance penetration in many countries is very low. The assurance of government intervention coupled with the lack of effectiveness of the financial transaction negated any incentive for individuals to acquire a cat insurance policy. Other elements were also at play in affecting the business case for earthquake insurance:

- The fact that the events are rare reduced the public awareness (i.e., it will not happen in my lifetime)

- The perception that I am fine because my property/business was not affected in the last event. It only happened to others

- The perception that construction codes provided "disaster-proof" structures

- A general "chronic" awareness about cat insurance and cat risk among the general public

- High cost-For a large segment of society the cost of cat insurance is not affordable.

The introduction of cat models in the early nineties revolutionized the Cat insurance business by providing physical approaches to modeling losses. Actuarial models, which were used by the insurance industry, were very poor indicators of future losses since cat events are rare events. The historical data is too sparse to yield reliable actuarial models making both pricing and reinsurance transactions highly uncertain. Cat models provided greater capabilities to link the physical characteristics of natural hazard events to the vulnerability of the exposed assets, thereby projecting future losses with greater accuracy, while enabling insurers to understand the spatial distribution of exposure and loss along the insurer's lines of business. Cat models provided a means to better anticipate the future and to quantify volatility. The cat models provided the tool to more accurately price cat risk and more efficiently transact contracts between all parties involved, particularly the insurer, reinsurer and investor. Cat models made new financial products such as Cat bond possible and opened the door for more effective financial transactions embedded in the indexed and parametric insurance products. These models significantly reduce the cost of an 
insurance transaction compared to the conventional indemnity practice. Further, they increase capacity for reinsurance while at the same time providing more peace of mind to the insured. It is these latest advances that have made insurance an essential parameter in resilience building.

\subsection{The New Dynamic in Cat Risk Financing}

Two successive early events were wake up calls for the insurance industry in its handling of cat risks: 1992 Hurricane Andrew and 1995 Northridge earthquake. These events demonstrated that extreme events could create devastating losses to society, and consequently to insurers. The immediate impact was in the universal shift of the insurance industry towards the use of cat models. Since then many catastrophic events have taken place around the globe and the cumulative losses have staggered prompting a rise in awareness among governments and the public, that new approaches for managing extreme events from natural hazards were needed.

New phenomena are also taking place that caused the increase awareness and the call for more action not only by the insurance industry but also by government.

- Urbanization is causing greater accumulation of assets in cities and urban agglomerations;

- Wealth accumulation and increases in the standards of living have increased the value of assets;

- Increase in the severity (and arguably frequency) of extreme weather events due climate change;

- Domino-effect due to the complexity of the urban environment that can multiply the losses.

Governments are finding it more and more costly to come after a disaster and pick up the bill. They are looking at ways to not only increase the role of insurance, but to incorporate risk financing as part of the tool set of financial instruments to reduce contingent liabilities, reduce the financial impact and improve recovery from disasters. They are also realizing that "physical protection" through infrastructure is not necessary full protection. Typhoon Hagibis of October 2019 in Japan caused more than 100 dikes to fail, at the time where the Japanese authorities thought that had controlled flood risk in the country through major multi-decades flood protection investments. In addition to strengthening physical infrastructure, countries are looking for new strategies to cover losses and to shift these losses from government to individuals, insurers and to the capital market. 


\subsection{TCIP as an Early Experiment}

TCIP is an early experiment aimed at increasing penetration by making cat insurance mandatory for homeowners in Turkey. This approach can be considered to represent the very first "line of defense" for government to reduce its contingent liability by shifting losses to the property owners and the insurance industry. The basic concept of insurance of spreading risk widely among as many policyholders as possible is applied, thereby reducing premium cost and making insurance affordable. Certain mechanisms are used to ensure that the property owner is obligated to contract insurance (e.g., linking insurance to real-estate transactions). While in its early stages, TCIP struggled to accomplish its goals, it has progressively build strength mostly through sound insurance practices, awareness raising, keeping affordability, and relying on scientific modeling. In 2016, TCIP has 136 billion Euro coverage capacity for earthquake losses in Turkey. A true evidence of resilience contribution to Istanbul and other major cities in Turkey since that capital can put back into the economy immediately after an earthquake with essentially zero cost to the government. Another significant advantage is that TCIP would put back its contribution to the regional and local economies since the direct impacts of an earthquake event are local and regional. The TCIP coverage capacity is a true evidence of resilience contribution to Istanbul, other major cities in Turkey and the country as a whole.

\subsection{More Innovation in the Market}

With the support of the World Bank and other international financial institutions (IFIs), more innovation is coming to the financing of disaster risk, by introducing sophisticated strategies and solutions aimed at reducing the transaction cost and building a greater demand. The underlying objective remains the protection of the state finances, individual assets, and the economy through sustainable and efficient risk financing mechanisms that cover projected disaster-related expenditures and at the same time, reduce volatility and increase predictability. Greater demand is accomplished through an increase in transparency and efficiency. The use of catastrophe loss models makes this achievable by providing scientifically auditable projections of losses and a rigorous mapping of characteristics and values of the exposed assets. The following provide a few examples of innovative disaster risk financing mechanisms that are aimed not only at providing liquidity after a disaster but also building resilience. 


\subsubsection{Indonesia: Pooling Fund Untuk Bencana-PFB}

Core to the government strategies for risk financing, is the establishment of the Pooling Fund for Disaster (Pooling Fund untuk Bencana-PFB) (World Bank 2020). The PFB is a dedicated disaster reserve fund (a 'pooling fund') aimed at strengthening the financial and fiscal resilience of the Government of Indonesia to natural disasters and health-related shocks. The pooling fund is expected to help improve disaster financing by:

(i) Enabling the government to accrue unspent budget allocations for disaster response to save for future years and build reserves;

(ii) Improving efficiency in the use of funds from the state budget for post-disaster expenditures through improved up front planning and budgeting;

(iii) Leveraging additional financial instruments by linking them directly to the pooling funds with clear and pre-agreed operating procedures (e.g. development partner contingent financing, market based risk transfer, or international assistance following events);

(iv) Connecting the pooling fund to clear pre-arranged disbursement channels and rules, thereby increased speed and transparency of post-disaster spending and providing predictability to implementing agencies on the availability of funds; and

(v) Increasing the ability to link risk financing to incentives and investment for all phases of disaster risk management, including preparedness and prevention.

While the PFB is still at the definition stage, it has secured a \$510 million funding commitment from the World Bank and is well embedded in the overarching government reforms on building fiscal, physical, and social resilience, which are outlined in the recently approved National MediumTerm Development Plan (RPJMN) for 2020-2024.

\subsubsection{Philippine: The Philippine City Disaster Insurance Pool (PCDIP)}

The Philippine City Disaster Insurance Pool (PCDIP) is a disaster risk financing (DRF) solution to enable immediate access to early recovery funding for cities in the Philippines (Asia Development Bank 2018). The pool is being developed by the Government of the Philippines with support from the Asian Development Bank. It is one element of the Government of the Philippines strategy to create catastrophe financial self-sufficiency of local government units-LGUs-(i.e., provinces and cities). Its innovation is that it brings LGUs together into a pool to create a DRF scheme that gives them quick access to funding for immediate emergency response action and early recovery. The PCDIP would provide immediate short term liquidity 
Fig. 12.4 Disaster risk financing instruments for cities (Philippine)
DRF instruments for cities

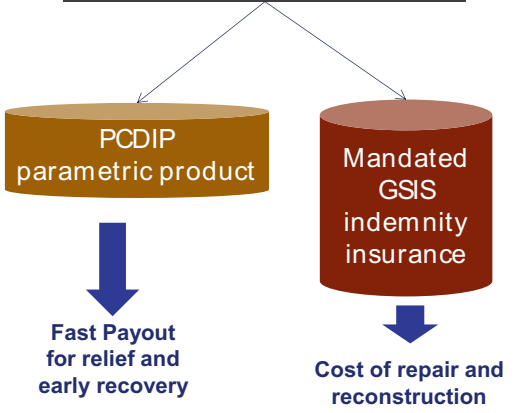

to city and provincial governments for the relief and early recovery phases of a disaster. A simple schematic on the functioning of the PCDIP is indicated in Fig. 12.4.

Earlier studies and recent events indicated that local governments that had cash in hands at the time of a disaster event, were able to recover faster than those who had to wait for an allocation from the central government budget. The PCDIP would complement existing disaster risk financing instruments including the Government Services Insurance System (GSIS) and would serve as an additional source of near-immediate liquidity in the event of a disaster. Initially, PCDIP covers two hazards: Tropical cyclone (wind speed) and earthquake (ground shaking). For each hazard cities can choose the level of premium that would pay for the combination of minimum and maximum payouts they would receive. These parameters are anchored on a modeled index parametric trigger structure. Recognizing that cities have different hazard levels and varying financial capacity, the design of the PCDIP attempts to provide a flexible, accessible and valuable insurance scheme; it offers certainty and speed in funding for pre-determined triggering events. Cities will know within days of a catastrophe event occurring what sum they will receive and then physically receive the cash shortly after. The PCDIP has not seen the day yet, but as a concept it is innovative and addresses a unique constituencies (i.e., local authorities) that are at the front line of disaster response and recovery.

\subsection{Conclusions}

Insurance and risk financing are important elements in building resilience. The overarching mission is to protect state finances, public and private assets and the economy of a country. Cat insurance is often ineffective in developing and emerging economies because it is not adequately regulated and managed and does not take advantage of the scientific knowledge offered by catastrophe loss models. Governments must look at cat insurance in the overall scheme of financing disaster risk and building resilience. This may require reforms in the insurance regulatory system that enables more innovation and reduces morale hazard. Through these steps, governments can 
more effectively deal with the escalating losses from disasters and reduce its contingent liability by shifting cost to individuals, insurance and the capital market. Recent examples show that innovation is bringing sustainable, transparent and efficient risk financing mechanisms at a lower cost than traditional insurance.

\section{References}

Asia Development Bank (2018). Philippine City Disaster Insurance Pool (PCDIP): Rationale and Design.

Bendimerad F and Hom S (1999). CATASTROPHE Modeling, Risk Management, 46(5):26.

Canabarro E, Finkemeier M, Anderson RR and Bendimerad F (2000). Analyzing insurance-linked securities, The Journal of Risk Finance, 1(2): 49-75.

World Bank (2020). Indonesia Disaster Risk Finance \& Insurance (P173249), Project Information Document (https://documents1.worldbank.org/curated/en/225361591241320010/pdf/ConceptProject-Information-Document-PID-Indonesia-Disaster-Risk-Finance-Insurance-P173249.pdf)

Open Access This chapter is licensed under the terms of the Creative Commons Attribution 4.0 International License (http://creativecommons.org/licenses/by/4.0/), which permits use, sharing, adaptation, distribution and reproduction in any medium or format, as long as you give appropriate credit to the original author(s) and the source, provide a link to the Creative Commons license and indicate if changes were made.

The images or other third party material in this chapter are included in the chapter's Creative Commons license, unless indicated otherwise in a credit line to the material. If material is not included in the chapter's Creative Commons license and your intended use is not permitted by statutory regulation or exceeds the permitted use, you will need to obtain permission directly from the copyright holder.

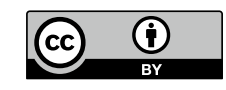

